\title{
Relação entre a patogenicidade do Schistosoma mansoni em camundongos e a susceptibilidade do molusco vetor. III. Mortalidade, pesos corporal e das vísceras*
}

\author{
Relationship between the pathogenicity of Schistosoma mansoni in mice and the \\ susceptibility of the vector mollusc. III. Mortality, body weight and viscera weights
}

\author{
Eliana Maria Zanotti-Magalhães, Luiz Augusto Magalhães, \\ Jose Ferreira de Carvalho
}
Departamento de Parasitologia do Instituto de Biologia da Universidade Estadual de Campinas (UNICAMP) - Campinas, SP - Brasil - (E. M. Z. M. L. A. M.),
Departamento de Estatística do Instituto de Matemática, Estatística e Ciências da Computaçăo da Universidade Estadual de Campinas (UNICAMP) - Campinas, SP - Brasil - (J.F. C.)

\begin{abstract}
Estudou-se a relaçāo entre o desenvolvimento da hepatomegalia, da esplenomegalia, peso corporal e taxa de mortalidade em camundongos experimentalmente infectados por Schistosoma mansonicom o grau de susceptibilidade de Biomphalaria glabrata $\theta B$. tenagophila nas quais se desenvolveram as cercárias infectantes respectivamente, das linhagens BH $\theta$ SJ. Foram utilizados como hospedeiro definitivo camundongos Swiss, SPF e como hospedeiros intermediários populaçōes de moluscos selecionados geneticamente para o caráter susceptibilidade. Foram observados menores pesos corporais e das vísceras em camundongos infectados com cercárias provenientes de moluscos que apresentaram elevado grau de susceptibllidade. A malor susceptibilidade dos moluscos à infecçăo pelo 5 . mansoni correspondeu a uma menor sobrevivéncia dos camundongos infectados. Os resultados fazem crer que a maior adaptaçāo do parasita ao hospedeiro intemediário, traduzidos pelas taxas mais elevadas de susceptibilidade, pode levar a um comportamento diferente deste parasita no hospedeiro definitivo.
\end{abstract}

Biomphalaria, parasitologia. Schistosoma mansoni, patogenicidade. Hepatomegalia, epidemiologia. Esplenomegalia, epidemiologia.

\section{Introdução}

Uma da principais manifestaçỏes clínicas da esquistossomose mansônica é o desenvolvimento da hepatosplenomegalia.

A hepatosplenomegalia é avaliada em trabalhos experimentais, com animais, através do peso do fígado e do baço. Se nessa importante manifestação clínica está envolvida a característica genética do hospedeiro vertebrado, o estágio de desenvolvimento da doença e a linhagem do parasita deverão também ser fatores a serem considerados (Warren ${ }^{16}, 1967$ ).

A observação de indivíduos que desenvolvem hepatosplenomegalia compensada nas áreas endêmicas abrangidas pela linhagem SJ do $S$. mansoni é rara (Santos ${ }^{14}, 1967$; Lima ${ }^{9}, 1991$ ), enquanto em áreas dominadas pela linhagem BH se observam indivíduos com hepatosplenomegalia descompensada.

No presente trabalho procurou-se verificar a existência de relação entre o desenvolvimentno de hepatosplenomegalia com a suscetibilidade do molusco vetor que produziu as cercárias infectantes para o hospedeiro vertebrado. Observou-se tambem a mortalidade dos camundongos e seu peso corporal.

\section{Material e Método}

Moluscos B. glabrata e B. tenagophila foram selecionados geneticamente por processo de

*Pesquisa financiada pela Financiadora de Estudos e Projetos (FINEP) - Processo $n^{\circ} 43.810417-0$ e pelo Conselho Nacional de Desenvolvimento Cient(fico e Tecnologico (CNPq) - Processo n ${ }^{\circ} 40.0798 .85$

Separatas/Reprints: Eliana Maria Zanotti-Magalhàes - Cidade Universitaria - Barāo Geraldo - Caixa Postal 6109 - $13083-970$ -

Campinas, SP - Brasil - Fax: (0192) 39-3124

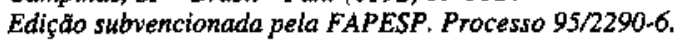

Recebido em 18.1.1995. Aprovado em 31.5.1995 
autofecundação, para o caráter susceptibilidade. Obtiveram-se dessa forma, para cada espécie, 5 progenies de moluscos, que foram expostos a 10 miracídios das linhagens $\mathrm{BH}$ e SJ, respectivamente.

As cercárias obtidas de cada espécie de molusco e sua progenie foram utilizadas para infecçăo de camundongos Swiss, SPF, formando-se os seguintes grupos:

Camundongos infectados com a linhagem $\mathrm{BH}$ :

- 20 camundongos infectados com cercárias da geração parental (BHP).

- 19 camundongos infectados com cercárias da geração $\mathrm{F}_{1}\left(\mathrm{BHF}_{1}\right)$.

- 20 camundongos infectados com cercárias da geraçâo $\mathrm{F}_{2}\left(\mathrm{BHF}_{2}\right)$.

- 27 camundongos infectados com cercárias da geração $\mathrm{F}_{3}\left(\mathrm{BHF}_{3}\right)$.

- 25 camundongos infectados com cercárias da geração $\mathrm{F}_{4}\left(\mathrm{BHF}_{4}\right)$.

Camundongos infectados com a linhagem $\mathrm{SJ}$ :

- 14 camundongos infectados com cercárias da geração parental (SJP).

- 18 camundongos infectados com cercárias da geraçāo $\mathrm{F}_{1}\left(\mathrm{SJF}_{1}\right)$.

- 19 camundongos infectados com cercárias da geraçâo $\mathrm{F}_{2}\left(\mathrm{SJF}_{2}\right)$.

- 18 camundongos infectados com cercárias da geração $\mathrm{F}_{3}\left(\mathrm{SJF}_{3}\right)$.

- 10 camundongos infectados com cercárias da geração $\mathrm{F}_{4}\left(\mathrm{SJF}_{4}\right)$.

Os subgrupos de camundongos foram constituídos a medida em que as cercárias foram sendo eliminadas pelos caramujos.

Os roedores foram infectados imergindo-se suas caudas em tubo de ensaio contendo suspensāo cercariana. Cada animal foi exposto a 100 cercárias.

Um terceiro grupo de camundongos foi constituido, denominado grupo controle, sem infecçāo por S. mansoni .

Ao fim de oito semanas, os roedores sobreviventes foram sacrificados. Por essa ocasião, foram registrados: peso corporal final, peso do fígado e peso do baço. O peso corporal inicial foi anotado por ocasião da infecção.

Os métodos de análise estatística dos dados utilizaram os procedimentos usuais de análise de variância. Procedeu-se, também, ao estudo dos efeitos de linhagem e de taxa de infecção dos moluscos em cada resposta. Os cálculos foram feitos com o software $\mathrm{SAS}^{\oplus}$, em computador compatível com IBM-PC.

\section{Resultados}

$\mathrm{Na}$ Tabela 1 estão apresentados os resultados referentes às taxas de infecçăo das geraçōes $P, F_{1}$, $\mathrm{F}_{2}, \mathrm{~F}_{3}$ e $\mathrm{F}_{4}$ de B. glabrata e B. tenagophila expostas às respectivas gerações de $S$. mansoni. A partir da geração $F_{1}$ observou-se acentuado aumento da susceptibilidade dos moluscos.

A taxa de mortalidade referente aos camundongos do grupo-controle e do grupo infectado com as linhagens BH e SJ de S. mansoni está apresentada na Tabela 2.

O estudo estatístico realizado considerou os resultados dos camundongos infectados desde que não tenham ocorrido mortes no grupo de camundongos não submetidos à infecção pelo $S$. mansoni.

Através da Tabela 3, verifica-se que a taxa de infecção dos moluscos foi parâmetro significativo ( $\mathrm{p}<4 \%$ ) na morte dos camundongos. Foi observado que a taxa de mortalidade apresentada por camundongos infectados com a geração parental do parasita foi menor e significativamente diferente da taxa de mortalidade observada nos grupos de camundongos infectados com $\mathrm{S}$. mansoni das gerações $F_{1}, F_{2}, F_{3}$ e $F_{4}$.

Nas Tabelas 4 e 5 estão apresentadas as médias referentes aos pesos corporal e das vísceras dos camundongos infectados por cercárias de S. mansoni das linhagens $\mathrm{BH}$ e SJ, provenientes de moluscos das gerações $P, F_{1}, F_{2}, F_{3}$ e $F_{4}$. Constam também desta tabela, os resultados referentes ao grupo de

Tabela 1 - Taxa de infecção das geraçōes de B. glabrata $\theta$ B. tenagophila submetidas à infecçăo pelas correspondentes geraçöes de $S$. mansoni, respectivamente das geraçסes BH e SJ.

\begin{tabular}{lcccc} 
Espécie & $\begin{array}{c}\text { Geraçāo } \\
\text { dos moluscos } \\
\text { e do S. mansoni }\end{array}$ & $\begin{array}{c}\text { No de moluscos } \\
\text { examinados }\end{array}$ & $\begin{array}{c}\text { No de moluscos } \\
\text { que eliminaram } \\
\text { cercárias }\end{array}$ & $\begin{array}{c}\text { Taxa de infecçāo } \\
(\%)\end{array}$ \\
\hline B. glabrata & $\mathrm{P}$ & 50 & 22 & 44 \\
& $\mathrm{~F}_{1}$ & 29 & 20 & 69 \\
& $\mathrm{~F}_{2}$ & 66 & 48 & 73 \\
B. tenagophila & $\mathrm{F}_{3}$ & 19 & 14 & 74 \\
& $\mathrm{~F}_{4}$ & 20 & 12 & 60 \\
& $\mathrm{P}$ & 59 & 9 & 15 \\
& $\mathrm{~F}_{1}$ & 72 & 35 & 49 \\
& $\mathrm{~F}_{2}$ & 47 & 28 & 60 \\
& $\mathrm{~F}_{3}$ & 52 & 35 & 67 \\
& $\mathrm{~F}_{4}$ & 27 & 7 & 26
\end{tabular}


Tabela 2 -Taxa de mortalidade apresentada por camundongos infectados com S. mansoni das linhagens BH e SJ e por camundongos do grupo controle.

\begin{tabular}{ccccc}
$\begin{array}{c}\text { Grupos de } \\
\text { camundongos }\end{array}$ & $\begin{array}{c}\text { Geraçāo } \\
\text { do } S \text {. mansoni }\end{array}$ & $\begin{array}{c}\mathrm{N}^{2} \text { de } \\
\text { camundongos } \\
\text { experimentados }\end{array}$ & $\begin{array}{c}\mathrm{N}^{2} \text { de } \\
\text { camundongos } \\
\text { mortos }\end{array}$ & $\begin{array}{c}\text { Taxa de } \\
\text { mortalidade (\%) }\end{array}$ \\
\hline BH & $\mathrm{P}$ & 20 & 3 & 15,0 \\
& $\mathrm{~F}_{1}$ & 19 & 7 & 36,8 \\
& $\mathrm{~F}_{2}$ & 20 & 10 & 50,0 \\
SJ & $\mathrm{F}_{3}$ & 27 & 9 & 33,3 \\
& $\mathrm{~F}_{4}$ & 25 & 15 & 60,0 \\
& $\mathrm{P}$ & 14 & 2 & 14,3 \\
& $\mathrm{~F}_{1}$ & 18 & 4 & 22,2 \\
& $\mathrm{~F}_{2}$ & 19 & 8 & 52,1 \\
& $\mathrm{~F}_{3}$ & 18 & 9 & 20,0 \\
\hline Controle & $\mathrm{F}_{4}$ & 10 & 2 & 0
\end{tabular}

Tabela 3 - Análise de variância considerando a mortalidade dos camundongos.

\begin{tabular}{cccc} 
Fonte de variaçăo & Graus de liberdade & Qui-quadrado & Probabilidade \\
\hline Intercepto & 1 & 17,13 & 0,00 \\
Linhagem & 1 & 2,80 & 0,09 \\
Taxa & $\mathbf{8}^{*}$ & 16,41 & 0,04
\end{tabular}

*O modelo é saturado e contém parâmetros redundantes, devido à estrutura de dados

Tabela 4 - Peso corporal médlo de camundongos submetidos ou nåo à infecção por S. mansoni.

\begin{tabular}{lccc} 
Grupos & $\begin{array}{c}\text { Geraçăo do } S . \\
\text { mansoni }\end{array}$ & Inicial & Peso corporal $(\mathrm{g})$ \\
\hline $\mathrm{BH}$ & $\mathbf{P}$ & $18,85 \pm 0,85$ & Final \\
& $\mathrm{F}_{1}$ & $17,61 \pm 0,70$ & $29,13 \pm 2,36$ \\
& $\mathbf{F}_{2}$ & $17,24 \pm 0,78$ & $25,25 \pm 4,26$ \\
& $\mathrm{~F}_{3}$ & $17,42 \pm 0,92$ & $20,02 \pm 2,92$ \\
S.J & $\mathrm{F}_{4}$ & $17,01 \pm 0,83$ & $22,20 \pm 3,58$ \\
& $\mathbf{P}_{1}$ & $18,27 \pm 0,96$ & $23,83 \pm 4,45$ \\
& $\mathrm{~F}_{1}$ & $17,33 \pm 0,86$ & $26,39 \pm 2,00$ \\
& $\mathrm{~F}_{2}$ & $17,48 \pm 0,84$ & $22,94 \pm 4,78$ \\
& $\mathrm{~F}_{3}$ & $17,22 \pm 0,96$ & $21,30 \pm 2,54$ \\
& $\mathrm{~F}_{4}$ & $17,95 \pm 0,84$ & $22,04 \pm 2,56$ \\
Controle & - & $18,30 \pm 1,27$ & $25,83 \pm 2,04$ \\
\hline
\end{tabular}

Tabela 5 - Peso médio do fígado e do baço de camundongos submetidos ou nāo à infecçăo por $S$. mansoni.

\begin{tabular}{cccc} 
Grupos & Geraçăo do S. mansoni & Peso do Figado $(\mathrm{g})$ & Peso do Baço $(\mathrm{g})$ \\
\hline BH & $\mathrm{P}$ & $2,7835 \pm 0,42$ & $0,6077 \pm 0,17$ \\
& $\mathrm{~F}_{1}$ & $2,1452 \pm 0,55$ & $0,4110 \pm 0,15$ \\
& $\mathrm{~F}_{2}$ & $1,6278 \pm 0,38$ & $0,2765 \pm 0,09$ \\
& $\mathrm{~F}_{3}$ & $2,1391 \pm 0,57$ & $0,3717 \pm 0,15$ \\
SJ & $\mathrm{F}_{4}$ & $2,3403 \pm 0,61$ & $0,4860 \pm 0,18$ \\
& $\mathrm{P}$ & $2,1359 \pm 0,34$ & $0,3809 \pm 0,12$ \\
& $\mathrm{~F}_{1}$ & $1,9259 \pm 0,60$ & $0,3313 \pm 0,16$ \\
& $\mathrm{~F}_{2}$ & $1,6088 \pm 0,30$ & $0,2931 \pm 0,10$ \\
& $\mathrm{~F}_{3}$ & $1,6012 \pm 0,34$ & $0,2859 \pm 0,17$ \\
& $\mathrm{~F}_{4}$ & $2,2383 \pm 0,33$ & $0,3816 \pm 0,17$ \\
\hline Controle & - & $1,5461 \pm 0,20$ & $0,1889 \pm 0,04$
\end{tabular}


Tabela 6 - Análise de variância (soma dos quadrados do tipo ill) por respostas.

Resposta/Fonte
de variação

Peso Corporal Final

Peso do Fígado

\begin{tabular}{lllll}
\hline Valor Nivel $P$ & Valor & Nivel P & Valor Nivel P
\end{tabular}

Peso do Baço
Linhagem

Soma dos

quadrados

Graus de

liberdade

Taxa

(linhagem)

Soma dos

quadrados

Graus de

liberdade

Residuo

Soma dos

quadrados

Graus de

liberdade

camundongos não submetidos à infecçāo pelo $S$. mansoni (Grupo-controle).

A Tabela 6 contém os resultados da análise estatística com referência aos pesos corporal final e das vísceras. A média obtida para o peso corporal final no grupo-controle foi significativamente maior (a nível de $5 \%$ ) do que as médias obtidas para as linhagens BH e SJ. Camundongos infectados com a linhagem $\mathrm{BH}$ apresentaram peso corporal final significativamente maiores do que camundongos infectados com a linhagem SJ.

A infecção por S. mansoni provocou aumento significativo no peso do fígado e do baço, sendo que camundongos infectados com a linhagem $\mathrm{BH}$ apresentaram um aumento maior do peso do fígado e do baço que camundongos infectados com a linhagem SJ.

A taxa de infecção apresentada pelos moluscos, nos quais se originaram as cercárias, que foram utilizadas na infeç̧ão dos camundongos, foi parâmetro significante, verificando-se menores pesos corporal e das vísceras com o aumento da susceptibilidade dos caramujos.

\section{Dlscussăo e Conclusões}

A verificaçăo do peso do fígado e do baço dos camundongos infectados com S. mansoni é critério de avaliação do desenvolvimento da hepatomegalia e da esplenomegalia tambem, comumente observadas em pacientes humanos.

Warren $^{16}(1967)$, estudando a esquistossomose em camundongos infectados com as linhagens de Porto Rico, Brasil, Egito e Tanzânia, verificou esplenomegalia significante mesmo nos animais infectados com um par de vermes. A hepatomegalia foi observada em todos os animais, exceto naqueles infectados com a linhagem egípcia. As linhagens brasileira e portorriquenha induziram maior aumento do fígado, que foi acompanhado, no caso da linhagem brasileira, por fibrose acentuada. A linhagem egípcia induziu aumento menor do fígado, apresentando também menores granulomas. Em estudo quantitativo, realizado através de autopsias de indivíduos infectados, Cheever ${ }^{4}$ (1968) verificou que, mesmo quando os pesos do fígado e do baço não estavam aumentados, a fibrose de Symmers estava presente.

O aumento do peso do fígado e do baço foi verificado por Powers e Cheever ${ }^{13}$ (1972), ao estudar o desenvolvimento do $S$. mansoni em várias linhagens em macacos.

Segundo observaçỗes de Magalhães e col. ${ }^{10}$ (1975), camundongos infectados com S. mansoni das linhagens $\mathrm{BH}$ e SJ apresentaram fígado maior em relação aos camundongos não infectados pelo trematódeo.

Conforme verificado por Andrade ${ }^{1}$ (1962), a esplenomegalia observada em camundongos esquistossomóticos é conseqüência da hiperplasia das células do sistema reticuloendotelial, e da congestāo venosa que aparece tardiamente e se manifesta pela dilatação dos seios venosos, com hiperplasia e hipertrofia da trama reticular.

Os resultados apresentados nas Tabelas 5 e 6 , referentes aos pesos do fígado e do baço dos camundongos infectados, mostram a ocorrência de hepatomegalia e esplenomegalia, incidindo de maneira mais acentuada nos animais infectados com a linhagem $\mathrm{BH}$. 
Os mecanismos imunologicos que envolvem a participação das células $T$ estão, de certo modo, relacionados com os pesos do fígado e do baço de camundongos infectados, uma vez que, em camundongos congenitamente atímicos e submetidos à infecção esquistossomotica, os pesos dessas vísceras săo menores do que aqueles verificados em camundongos que apresentam timo ou que tiveram o timo reconstituído através de enxerto (Phillips e col. ${ }^{11}, 1977$ ).

O ovo do trematódeo desempenha papel fundamental no desenvolvimento da hepatomegalia e da esplenomegalia esquistossomótica; nas infecções unissexuais observa-se apenas discreto aumento do fígado e do baço (Zanotti e col. ${ }^{17}, 1983$ ).

Comoé sabido, a esquistossomose hepatosplênica está relacionada com a resposta imunológica granulomatosa, mediada por células $\mathbf{T}$, observada em torno do ovo de $S$. mansoni depositado no fígado. Em consequiência das inúmeras reações granulomatosas no fígado, o funcionamento do orgão se altera, ocorrendo o aparecimento de hipertensåo portal e surgimento de circulaçāo colateral.

Camundongos destituídos de timo, timectomizados ou tratados com drogas imunossupressoras ou soro antilinfocito (Domingo e col. ${ }^{6}, 1967$; Domingo e Warren ${ }^{7.8}, 1968$; Byram e Lichtenberg ${ }^{2}$, 1977; Phillips e col. ${ }^{12}, 1980$ ) e infectados com $S$. mansoni apresentam redução no tamanho do granuloma. Segundo Phillips e col. ${ }^{11}$ (1977), acompanhando o tamanho reduzido do granuloma observado nos animais destituídos de timo, observa-se também diminuiçẫo da pressāo portal.

Menores valores dos pesos do fígado e do baço foram observados na presente pesquisa, quando os camundongos foram infectados com cercárias de $S$. mansoni, oriundas de moluscos das geraçōes $F_{1}, F_{2}$ e $F_{3}$ (Tabela 5) quando comparados com a geração parental. Pesos menores para as vísceras foram observados em camundongos cuja infecção foi realizada com cercárias oriundas dos moluscos que alcançaram as mais altas taxas de infecção (Tabela 1). Paralelamente, os menores diâmetros médios dos granulomas hepáticos e esplênicos foram observados nos camundongos infectados com cercárias de moluscos das geraçōes $\mathrm{F}_{2}$ e $\mathrm{F}_{3}$ (Zanotti-Magalhães e col. ${ }^{18}, 1993$ ).

DeWitt e Warren ${ }^{5}$ (1959) e Cheever ${ }^{3}(1965)$ referem que há relação entre a hipertensão portal e o tamanho das reaçőes granulomatosas. Com base nessas observaçōes, é de se supor que os menores pesos do fígado e do baço, no presente trabalho verificados em camundongos infectados com cercárias oriundas de moluscos mais susceptíveis, parecem ser consequiência do menor tamanho dos granulomas no parênquima hepático, o que de alguma forma acarretaria uma menor hipertensão portal e, assim, menor congestão venosa.
O peso corporal dos camundongos infectados, quando comparado com o peso dos animais sadios, constitui parâmetro importante no quadro da esquistossomose. Conforme o apresentado na Tabela 4, a infeç̧āo esquistossomótica determinou peso corporal menor do que o de camundongos sadios e a susceptibilidade maior do molusco à infecção esquistossomótica acarretou menor crescimento ponderal do hospedeiro definitivo durante a evolução do parasita em seu organismo.

A mortalidade verificada nos animais infectados com S. mansoni é sobretudo uma conseqüência da presença dos ovos do parasita no organismo do hospedeiro (Zanotti e col. ${ }^{17}, 1983$ ).

Nāo obstante o tamanho da reaçāo granulomatosa estar diminuído, a pressāo portal estar reduzida e ser menor o tamanho do fígado e do baço em camundongos destituf́dos de linfócitos $T$, lesóes hepatocelulares causadas por ação de substâncias emanadas dos ovos e maior susceptibilidade a outros agentes infecciosos podem explicar a menor sobrevida dos animais.

Como reforça a análise estatística (Tabela 3 ) à maior susceptibilidade de $B$. glabrata e $B$. tenagophi$l a$, corresponde a uma menor sobrevivência dos camundongos infectados. A maior nocividade da infecção esquistossomótica no hospedeiro vertebrado parece ter estreita relação com a reação granulomatosa em seus tecidos, uma vez que a maior mortalidade observada em camundongos corresponde a uma menor reaçāo imune celular em torno do ovo do parasita (Zanotti-Magalhães e col. ${ }^{18}$, 1993).

Os resultados obtidos no decorrer do experimento fazem crer que a maior adaptação do parasita no hospedeiro intermediário, traduzida pelas taxas mais altas de susceptibilidade apresentadas pelos moluscos das geraçðes $\mathrm{F}_{1}, \mathrm{~F}_{2}, \mathrm{~F}_{3}$ e $\mathrm{F}_{4}$ ao $\mathrm{S}$. mansoni, pode levar a um comportamento diferente deste mesmo parasita, quando desenvolve seu ciclo bio16 gico no hospedeiro definitivo. Saoud ${ }^{15}$ (1966) aventou essa hipótese como plausível para explicar as diferenças de infectividade e patogenicidade de diferentes linhagens de $S$. mansoni.

\section{Referências Bibliográficas}

1. ANDRADE, Z. A. Aspectos experimentais da esplenomegalia da esquistossomose. Rev. Inst. Med. Trop., 4: 249-55, 1962.

2. BYRAM, J. E. \& LICHTENBERG,F. V. Altered schistosoma granuloma formation in nude mice. Am. J. Trop. Med. Hyg., 26: 944-56, 1977.

3. CHEEVER, A. W. A comparative study of Schistosoma mansoni infections in mice, gerbils, multimamate, rats and hamsters. I. The relation of portal hypertension to size of hepatic granuloma. Am. J. Trop. Med Hys., 14: 211-26, 1965.

4. CHEEVER, A. W. A quantitative post-mortem study of schistosomiasis in man. Am. J. Trop. Med. Hyg., 17: 38-64, 1968. 
5. De WITT, W. B. \& WARREN, K. S. Hepatosplenic schistosomiasis in mice. Am. J. Trop. Med. Hyg. 8: 440-6, 1959.

6. DOMINGO, E. O.; COWARD, R. B. T.; WARREN, K. S. The inhibition of granuloma formation around $\mathbf{S}$ chisto. soma mansoni eggs. I. Immunossupressive drugs. Am. J. Trop. Med. Hyg., 16: 284-92, 1967.

7. DOMINGO, E. O. \& WARREN, K. S. Endogenous desensitization: changing hos! granulomatous response to schistosome eggs at different stages of infection with Schistosoma mansoni. Am. J. Pathol., 52: 369$79,1968$.

8. DOMINGO, E. O. \& WARREN, K. S. The inhibition of granuloma formation around Schistosoma mansoni eggs. III. Heterologous anti-lymphocyte serum. Am. J. Pathol., 52: 613-31, 1968

9. LIMA, J. N. Estudo clínico e terapêutico da esquistossomose mansônica em menores de 15 anos do Vale do Ribeira, SP : comparação de oxamniguine, praziguantel e associação dessas drogas em baixas doses. Campinas, 1991. [Dissertação de Mestrado - Faculdade de Ciências Médicas , UNICAMP].

10. MAGAL.HĂES, L. A.; ALCÂNTARA, F. G.; CARVALHO, J. F. Alguns dados referentes ao estudo parasitologico e anatomopatologico de duas linhagens de Schistosoma mansoni, Sambon, 1907. Rev. Saúde Pública, 9: 1-5, 1975.

11.PHILLIPS, S. M.: DICONZA, J. J.: GOLD, J. A.; REID, W, A. Schistosomiasis in the congenitically athymic (nude) mouse. I. Thymic dependency of eosinofilia granuloma formation and host morbidity. J. Immunol., 118: 594-9, 1977.

12.PHILLIPS, S. M.; REID, W. A.; DOUGHTY, B. L.;
BENTLEY, A. G. The immunologic modulation of morbidity in schistosomiasis. Studies in athymic mice and in vitro granuloma formation. Am. J. Trop. Med. Hyg., 29: 820-31, 1980.

13. POWERS, K. G. \& CHEEVER, A. W. Comparison of geographical strains of Schistosoma mansoni in the Rhesus monkey. Bull. World. Health. Organ, 46: 295300,1972

14. SANTOS, N. R. Esquistossonose mansônica autóctone no Vale do Médio Paraiba, Estado de São Paulo, Brasil: contribuição para o estudo da zona endêmica. Sð̃o Paulo, 1967. [Tese de Doutorado - Faculdade de Medicina da USP].

15. SAOUD, M. F. A. The infectivity and pathogenicity of geographical strains of Schistosoma mansoni. Trans. $R$. S. Trop. Med. Hyg. 60: 585-600, 1966.

16. WARREN, K. S. A comparison of Puerto Rican, Brazilian, Egyptian and Tanzanian strains of Schistosoma mansoni in mice: penetration of cercariae, maturation of schistosomes and of liver disease. Trans. R. S. Trop. Med. Hyg., 61: 795-802, 1967.

17.ZANOTTI, E. M.; MAGALHÃES, L. A.; PIEDRABUENA, A. E. Avaliaçăo da patogenicidade decorrente da infecçăo pelo Schistosoma mansoni Sambon, 1907, agente de infeç̋̈es unissexuais em Mus muscultus. Rev. Saúde Pública, 17: 394-405, 1983.

18. ZANOTTI-MAGALHĀES, E. M.; MAGALHÃES, L. A.; CARVALHO, J. F. Relaçāo entre a patogenicidade do Schistosoma mansani em camundongos e a susceptibilidade do molusco vetor. II. Numero de ovos nas fezes e número e tamanho dos granulomas nas visceras. Rev. Saúde Pública, 27: 412-20, 1993.

\section{Abstract}

The relationship between the development of hepatomegaly, splenomegaly, body weight and mortality rate and the degree of susceptibility of Biomphalaria glabrata and B. tenagophila at which infective cercariae developed was studied. The study utilized Swiss mice, SPF, as definitive hosts and populations of snails genetically selected for cheracter susceptibility as intermediate hosts. Low body weight and smaller viscera were observed in infected mice with cercariae originating from snails that showed a high degree of susceptibility. The higher susceptibility of molluscs infected with S. mansoni corresponded to a lower survival of the infected mice. These results lead to the conclusion that the higher degree of adaptation of the parasite to its intermediate hosts, evidenced by the high indexes of susceptibility, leads to difterent behaviour on the part of this parasite in its definitive host.

Biomphalaria, parasitology. Schistosoma mansoni, pathogenicity. Hepatomegaly, epidemiology. Splenomegaly, epidemiology. 